\title{
The Stress Factor: Exploring the Possibility of a Psychological Component to Cancer
}

\author{
Bernard M. Edelstein, MD \\ Beth Israel Hospital, Boston Massachusetts
}

Follow this and additional works at: https://jdc.jefferson.edu/jeffjpsychiatry

Part of the Psychiatry Commons

Let us know how access to this document benefits you

\author{
Recommended Citation \\ Edelstein, MD, Bernard M. (1986) "The Stress Factor: Exploring the Possibility of a Psychological \\ Component to Cancer," Jefferson Journal of Psychiatry. Vol. 4 : Iss. 1 , Article 6. \\ DOI: https://doi.org/10.29046/JJP.004.1.003 \\ Available at: https://jdc.jefferson.edu/jeffjpsychiatry/vol4/iss1/6
}

This Article is brought to you for free and open access by the Jefferson Digital Commons. The Jefferson Digital Commons is a service of Thomas Jefferson University's Center for Teaching and Learning (CTL). The Commons is a showcase for Jefferson books and journals, peer-reviewed scholarly publications, unique historical collections from the University archives, and teaching tools. The Jefferson Digital Commons allows researchers and interested readers anywhere in the world to learn about and keep up to date with Jefferson scholarship. This article has been accepted for inclusion in Jefferson Journal of Psychiatry by an authorized administrator of the Jefferson Digital Commons. For more information, please contact: JeffersonDigitalCommons@jefferson.edu. 


\title{
The Stress Factor: Exploring the Possibility of a Psychological Component to Cancer
}

\author{
Bernard M. Edelstein, M.D.
}

I don't get depressed. I grow a tumor instead.

Woody Allen

For this is the great error of our day in the treatment of the human body that physicians separate the soul from the body (1).

As dwellers in the same house, it seems only logical that psyche and soma would be interdependent, that well-being in one would promote health in the other, and that illness in one would soon become manifest in its partner. Yet quantifying this intuitive relationship has long been a difficult task. Establishing a mechanism for disease-heart disease, infectious disease, neoplastic diseasewhich can withstand the scrutiny of experimental rigor, is difficult enough. To introduce a seemingly not quantifiable entity such as psychology in the form of stress or anxiety presents such great complexity that for a long time it seemed that the relationship between mind and body would remain a purely speculative one.

From the time of Galenus, physicians have suspected that certain psychological factors resulted in a predisposition to cancer. Galenus wrote that "melancholic women were more prone to cancer than those of sanguine temperament" (2). In 1853, James Paget, the English surgeon and pathologist, wrote: "The cases are frequent in which deep anxiety, deferred hope, and disappointment are quickly followed by the growth or increase of cancer. That we can hardly doubt that mental depression is a weighty addition to the other influences that favor the development of the cancerous constitution" (3).

In the last few years there has been a significant attempt to move the connection between stress and cancer out of the realm of speculation. Proponents of the psychoneuroendocrine model seek to establish a logical continuum from psychological stress to depressed immune response, mediated by neuroendocrine changes occurring in an hypothalamic-pituitary-adrenal pathway $(4,5)$. In considering the immune surveillance theory of cancer etiology, and the role of the immune system in suppressing oncogenic viruses, one must also consider the implications of a stress-induced immune deficiency.

Dr. Edelstein is currently doing a medical internship. He will be a second-year resident in psychiatry at Beth Israel Hospital, Boston, Massachusetts. 
There exist numerous difficulties in measuring the array of factors along this pathway. Establishing a clear definition of stress involves an appreciation for the many variables of human suffering in both its physiological and psychological forms. Although it is important to recognize the relationship between these factors, in any controlled experiment a distinction between psychological and physical insult must be made. If an electric shock is applied as a stressor in an animal study, it must be ascertained whether the shock produces any primary physiological damage or if the response is confined to an evocation of anxiety. In controlling for psychological stress, the experimenter must be cognizant of the roles of age, sex, circadian rhythms, and chronicity. As sophistication increases, researchers become aware of previously overlooked variables, so that new insights often invalidate more historical studies.

There is increasing facility in quantifying change in neuroendocrine levels, but appreciating the combined effect of several concurrently changing hormones is still puzzling. Finally, the role of immunology in cancer etiology is so complex and rapidly changing that it is hard to correlate proven examples of stress induced immune deficiency with specific neoplastic processes.

Actual quantification of stress-induced physiological change is fairly recent. In the 1950's, duodenal ulcer was hypothesized to be of psychosomatic origin (6). During the same period, Hans Selye's work demonstrated the "stress syndrome" in which experimental stressors led to adrenal hypertrophy, elevated blood corticosteroid levels, and thymic involution (7). In 1977, Monjan et al. found that acute exposure of mice to an auditory stressor resulted in an increase in circulating levels of plasma cortisol which produced a clear depression in lymphocyte-mediated cytotoxic response (8). Elevated levels of corticosteroids also produce secondary effects in macrophage activity, B cells, and natural killer (NK) cells. McMaster and Franzi have postulated that corticosteroids interfere with the antibody-antigen response either through direct inhibition of antibody synthesis or by altering antigenic activity (9).

In addition to considering the apparently numerous effects of elevated cortisol levels on immune suppression, it is important to note that certain lymphocytes contain cholinergic and B-adrenergic receptor sites (10). Thus, stimulation of the sympathetic nervous system, long recognized as a barometer for stress, could act as a further modifier of lymphocyte activity. A 1976 study showed that rats injected with epinephrine displayed decreased lymphocyte response to either artificial (PHA) or natural antigen (11). Animal and human studies have confirmed the effects of stress on immunologic activity. In 1980, Hara found that rats exposed to a fifteen-day activity stress procedure suffered impaired immunologic status as demonstrated by decreased spleen and thymus weights and increased weight of the adrenal glands (12). In another recent study, rats subjected to housing stress, crowding, and isolation exhibited a decreased in vitro reactivity of lymphocytes to antigen.

In Bartrop's bereavement study, 26 bereaved spouses were monitored to ascertain the effect of severe stress on the immune system. At eight weeks after 
bereavement there was a tenfold suppression in T-cell response to concanavalin $\mathrm{A}$ and PHA as compared to the controls. No difference was found in numbers of $\mathrm{T}$ and $\mathrm{B}$ cells, or in cortisol, growth hormone, or thyroid hormone levels (13).

In assessing the effects of psychological stress, a number of variables become apparent. Monjan et al. studied comparative responses to acute vs. chronic stress. While acute exposure of mice to a sound stressor resulted in increased blood cortisol levels with accompanying depressed lymphocyte activity, long-term exposure to the same stressor prompted an enhancement of lymphocyte response (8). The suggestion is that the animal can learn to adapt physiologically to a psychological insult. The role of a coping mechanism is a particularly relevant consideration in humans. A study by Locke showed a significant decrease in the natural killer cell activity among highly-stressed college students who were assessed to have poor coping mechanisms (14). Stress in humans, then, is less a function of the insult itself than of how the insult is perceived and handled.

In exploring the role of the neuroendocrine system in the pathway from psychological insult to immune depression, experimental work has been directed towards stress-related modulations of a range of pituitary hormones. Levels of growth hormone, adrenocorticotropic hormone, prolactin, thyroid stimulating hormone, and testosterone have all shown response to stress $(6,15,16,17)$. A challenge lies in understanding the relationship of these hormones and their effect on the "immunologically competent cell" (4). Regarding the hypothalamus as a possible mediator in behaviorally-induced changes in immune response, Stein has shown that electrolytic lesions in the anterior basal hypothalamus of guinea pigs resulted in protection against lethal anaphylactic response, as well as decreased titers of circulating antibody and depressed delayed hypersensitivity reactions (18).

Having considered the mechanisms linking stress to the suppression of immune response, it is necessary to explore how a change in immunological competence influences neoplastic processes. In 1981, Penn presented three currently dominant theories: defective immunoregulation, chronic antigenic stimulation, and infection with oncogenic viruses (19). Non-sensitized and sensitized cytotoxic T-lymphocytes, macrophages, and natural killer cells have all been shown to inhibit tumor growth and metastases, and even to destroy existing tumor masses $(20,21,22,23)$. Research on the role of natural killer cells has culminated in the hypothesis that these unique anti-tumor cells represent a first line surveillance system outside of the conventional immune system which destroys malignant cells by lysis upon direct contact (20).

A number of researchers have gone beyond a study of stress and its effect on immunological competence, and have looked for a direct correlation between stress and cancer. In 1959, Levine showed that early chronic stress led to shorter survival times in mice implanted with leukemia (24). More recently, Riley found that steroid injection seven days after tumor implantation resulted in suppression of the immune system and enhanced tumor growth (5). Sklar, evaluating the 
effects of "social stress" on tumor growth in mice, found that the stress of social isolation increased tumor growth. Yet it was not isolation per se which affected tumor growth, but abrupt change in social conditions. Mice raised in isolation, or living in long-term isolation, had tumor growth which matched the controls. Those transferred from group to isolated living showed pronounced exacerbation of tumor growth. Sklar also found that stressed mice living in group housing demonstrated a marked difference in tumor growth, based on their "coping mechanisms": stressed mice who engaged in persistent fighting displayed no change in tumor growth, whereas stressed non-fighters manifested marked acceleration in tumor growth (25).

In Visintainer's study of escapable vs. inescapable shock, an uncontrollable insult was followed by decreased immunologic competence, evidenced by a greater number of metastases. Rats exposed to inescapable shock were less than half as likely to reject implanted tumors as rats who could control whether or not they received a shock. Visintainer concluded that "experiencing an uncontrollable aversive event produces behavioral and physiological effects that do not occur when the event is controllable" (26). Thus, both Sklar and Visintainer have demonstrated that stress and concomitant coping patterns bear directly upon the immune system's capacity to defend against neoplastic growth.

Leshan found four psychological factors that he correlated with onset of cancer: recent loss of an important relationship; inability to express anger; unresolved conflict surrounding parental figures; and sexual disturbance (27). Other researchers theorized that cancer patients demonstrating depression and psychological dysfunction had a shorter survival time than those who had developed successful coping mechanisms $(28,29)$. In a 1963 study, Kissen postulated that the incidence of lung cancer was higher in males having a "restricted outlet for emotional expression" (30). Greer, studying women with neoplasias of the breast, found that women with malignancies were more likely to characteristically suppress anger than those with benign lesions (31). These patients, who had presented for biopsy upon the discovery of a breast mass, underwent psychological evaluation preoperatively; researchers were blind to the presumptive diagnosis. Over a two year post-operative period, patients with breast carcinoma who tended to suppress anger maintained elevated IgA levels. There exists a positive correlation between advancing metastatic breast disease and serum IgA levels. Pettingale theorized that emotional suppression of anger could, via a hypothalamic-pituitary pathway, influence IgA-secreting exocrine glands (32).

Any study attempting to link personality to cancer must examine whether a given personality trait preceded the cancer, was precipitated by a neuroendocrine imbalance secondary to an occult malignancy, or not related at all. Perhaps the most ambitious exploration of how psychological factors may influence the development of cancer is the ongoing prospective study by Carolyn Thomas. Beginning in 1947, Thomas evaluated 17 consecutive classes of medical students at Johns Hopkins University, surveying medical history as well as family 
structure, behavioral patterns, and anxiety; she used questionnaires, the Rorschach, and figure-drawing tests. Annual assessment of morbidity and mortality has revealed that persons who developed major cancer had a history of pathological family relationships, particularly a lack of closeness to their parents, as compared to healthy participants or those who developed other major medical illnesses.

Certainly no one is suggesting that stress alone causes cancer. Neither, hopefully, will anyone reach the conclusion drawn by Susan Sontag in Illness As Metaphor that by connecting cancer to psychological and emotional factors, one is making the cancer patient into a guilty party (36). For this is not a matter of blaming the victim or of presuming that the cancer patient is responsible for his own disease. Rather, in approaching the constellation of factors that result in neoplasia, one should consider that psychological stress may play an important role that may have therapeutic and preventative implications.

That our emotions influence our physical health is not a new idea; as we make our way from the intuition of Galenus to the elaboration of the psychoneuroendocrine model, we find before us an intriguing, necessary task.

\section{REFERENCES}

1. Osler W: Aequanimitas with other addresses to medical students, nurses and practitioners of medicine. Philadelphia, Blakiston, 1905

2. LeShan L: Psychological states as factors in the development of malignant disease: a critical review. J Nat Cancer Inst 22:1-18, 1959

3. Paget J: Lectures on surgical pathology, delivered at The Royal College of Surgeons of England. London, Longmans, 1863

4. Solomon GF, et al: Psychoneuroendocrinological effects on the immune response. Annu Rev Microbiology 35:155-184, 1981

5. Riley V: Psychoneuroendocrine influences on immunocompetence and neoplasia. Science 212:1100-1109, 1981

6. Mirsky A: The psychosomatic approach to the etiology of clinical disorders. Psychosomatic Med 19:424-430, 1957

7. Selye H: Stress and disease. Science 122:625-631, 1955

8. Monjan AA, et al: Stress induced modulation of the immune response. Science 196:307-308, 1977

9. McMaster PD, et al: The effects of adrenocortical steroids upon antibody formation. Metabolism 10:990-1005, 1961

10. Rogers MP, et al: The influence of the psyche and the brain on immunity and disease susceptibility: a critical review. Psychosomatic Med 41:147-164, 1979

11. Joasoo A, et al: Stress and the immune response in rats. Int Arch Allergy Apply Immunol 50:659-663, 1976

12. Hara C, et al: Influence of activity-stress on thymus, spleen and adrenal weights of rats. Physiol Behav 27:243-248, 1981

13. Bartrop RW, et al: Depressed lymphocyte function after bereavement. Lancet I:834-836, 1977

14. Locke SE, et al: Ann Meet Am Psychosomatic Soc, Washington, D.C. 1978 
15. Yalow RS, et al: Hormone and Met Res 1:3, 1969

16. Mandelbrote BM, et al: Emotional factors in Graves' disease. Psychosomatic Med $17: 109-117,1955$

17. Kreuz, et al: Suppression of plasma testosterone levels and psychological stress. Arch Gen Psych 26:479-482, 1972

18. Stein M: Influence of brain and behavior on the immune system. Science 191:435440,1976

19. Penn I: Depressed immunity and the development of cancer. Clin Exp Immun 46:459-474, 1981

20. Herberman RB, et al: Natural cell-mediated immunity. Adv Cancer Res 27:305, 1978

21. Oehler RJ, et al: Natural cell-mediated cytotoxicity in rats. III. Effects of immunopharmacologic treatments on natural reactivity and on reactivity augmented by polyinosinic-polycytidylac acid. Int J Cancer 21:221, 1978

22. Haller $\mathrm{O}$, et al: Role of non-conventional natural killer cells in resistance against syngeneic tumor cells in vivo. Nature 270:609-611, 1977

23. Behelak Y, et al: Immunocompetent cells in patients with malignant disease: The lack of naturally occurring killer cell activity in the unfractionated circulating lymphocytes from patients with chronic lymphatic leukemia (CLL). Cancer 38:2274-2277, 1976

24. Levine $S$, et al: Differential survival to leukemia as a function of infantile stimulation in DBA/2 mice. Proc Soc Exp Biol Med 102:53-54, 1959

25. Sklar LS, et al: Social stress influences tumor growth. Psychosomatic Med 42:347-365, 1980

26. Visintainer MA, et al: Tumor rejection in rats after inescapable or escapable shock. Science 216:437-439, 1982

27. LeShan L, et al: Brit J Med Psych 29:49-56, 1956

28. Klopfer B: J Prof Tech, 21:331-340, 1957

29. Bahnson CB: Emotional and personality characteristics of cancer patients in Oncologic Medicine Clinical Topics and Practical Management. Edited by Sutrick AI, Engstrom PF. Baltimore, University Park Press, 1976

30. Kissen D: Personality characteristics in males conducive to lung cancer. $\mathrm{Br} J \mathrm{Med}$ Psych 36:27-36, 1963

31. Greer S: Psychological attributes of women who develop breast cancer: a controlled study. J Psychosomatic Res 19:147-153, 1975

32. Pettingale KW, et al: Serum IgA and emotional expression in breast cancer patients. J Psychosomatic Res 21:395-399, 1977 